Canadian Journal of Action Research

Volume 21, Issue 2, 2021, pages 72-90

\title{
CULTIVATING INCLUSION: BELONGING AND AGENCY IN YOUNG BLACK MEN THROUGH CIVIC ACTION RESEARCH
}

\author{
Amanda Eppley \\ University of California, Berkeley \\ Blanca Gamez-Djokic \\ University of California, Berkeley \\ Deborah L. McKoy \\ University of California, Berkeley
}

\begin{abstract}
This paper examines how community-based civic action research can cultivate civic engagement, civic belonging, and shifts in civic stakeholders' perceptions of racially and economically minoritized youth's civic agency. Specifically, this paper examines the implementation of Youth, Research and Plan (YRP) - a community-based research methodology that cultivates equitable relationships between schools, cities, and communities by situating disenfranchised youth and their schools at the center of civic and urban planning - in a unique academic program focused on the development of Black manhood and achievement in a public high school. Using a Critical Race Theoretical application of Communities of Practice and drawing on qualitative data gathered over the course of two years, we show how YRP was instrumental in the development of three interrelated communities of practice that supported the youth's academic endeavors and civic agency and yielded important shifts in civic stakeholders' perceptions of and relations with Black urban youth.
\end{abstract}

Key WoRdS: Civic action research; Civic engagement; Communities of practice; Critical race theory

\section{INTRODUCTION}

Racially and economically minoritized youth are often excluded from discussions and decision-making on a civic level, which results in their exclusion from the civic sphere 
(McKoy \& Vincent, 2005, 2007; Vincent, 2006). As these youth make their way from home to school daily - crossing streets and segregative freeways, riding public transportation - they experience on both affective and physical levels the continuing effects of civic disinvestments in targeted communities that began centuries ago. As Pauline Lipman (2012) points out, urban reform initiatives and practices of civic disinvestment do not happen separately from education reform and public school disinvestment; rather, these processes occur in tandem. Thus, the civic exclusion that poor youth of color experience at the city level is also one that they experience in school. Increasingly, partnerships between schools, cities, and communities are one way that civic agents, local stakeholders, community members, families, and youths coalesce to foster collaborations to mobilize the necessary resources and social capital to protect the integrity of their community and schools.

This paper analyzes the implementation of Youth, Research and Plan (YRP) ${ }^{1}$, a youth community-based action research methodology driven by a desire to cultivate healthy and equitable relationships between schools, cities, and communities by situating disenfranchised young people and their schools at the center of civic and urban planning. This paper discusses findings from a two year case study in one public high school classroom in a unique academic program called Black Manhood Achievement (BMA) engaging in YRP to address authentic community challenges through collection and analysis of local data and "street science" (Coburn, 2006). Drawing on neighborhood data generated by socioeconomically and racially subjugated youth engaged in authentic community development through a curricularly-relevant project-based learning strategy gathered over the course of two years (2016-2018), this paper sheds light on the role of youth's sense of agency and civic identity development in data-driven place-making strategies and practices.

The overarching research question framing this paper is: How do young African American men cultivate a deeper sense of agency that fosters civic identity development when engaged in authentic civic action research?

\section{Conceptual Framework: A Critical Race Application of Communities of Practice}

Situated learning theories, such as legitimate peripheral participation in a community of practice (Lave \& Wenger, 1991) are formative to the YRP design and methodology. These theories suggest that through legitimate peripheral participation, learners enter a community and gradually take up its practices. Initially, people may participate in "peripheral" ways, working more on the sidelines, but over time, they develop the identity of membership and the central practices of the group. As individuals become members of a community with a common interest, they collaborate over an extended period of time, sharing ideas and strategies, determining solutions and building innovations (Lave \& Wenger, 1991). Communities of practice (CoP) is a helpful way of understanding how identity and knowledge develop not in isolation, but rather relationally through individuals' differentiated practice in the various communities through which they have membership and through which they cycle.

${ }^{1}$ All names of organizations and individuals are pseudonyms. 
However, scholars have debated the explanatory potential and leverage CoP offer towards understanding how power and difference mediate individuals' positionality, membership, and participation in various communities (Duguid, 2012; Flores, 2007; Storberg-Walker, 2008). Storberg-Walker (2008) suggests that the heuristic classification of CoP is not clear and questions the various classifications of CoP as a "theory," "perspective," or "guide," attributing difficulties around how to make sense of, and apply, CoP meaningfully and successfully given this classificatory ambiguity. Without an understanding of what exactly $\mathrm{CoP}$ is or how it is operationalized, $\mathrm{CoP}$ risks being "stretched beyond its appropriate domain" (p. 556) and being uncritically applied such that "communities of practice" is used as a label that implies equity of practice and knowledge production but flattens power differentials (a critique Wenger later acknowledged; see Wenger, 2010).

To date, scholarship on CoP has not substantially taken up issues of race and power, nor has it interacted with paradigmatic interventions like Critical Race Theory, which has had resounding implications across disciplines. How does $\mathrm{CoP}$ account for power differentials that emerge along class and racial lines? How can a CoP cohere across sectors and scales, where conflicting interests often result in distrust between poor urban communities, cities, and the state? How can a CoP be fostered across schools and cities when historically, the civic landscape is shaped and defined by exclusion of Black individuals (Lipsitz, 2007)? These questions are formative to the work and relationships that emerge through the YRP partnership and serve to orient the conceptual and methodological approach of this case study, a critical race application of communities of practice.

Ladson-Billings and Tate (1995) identify the following three points as the organizing principles of CRT in Education: "1) Race continues to be a significant factor in determining inequity in the U.S., 2) U.S. society is based on property rights, 3) The intersection of race and property creates an analytic tool through which we can understand social (and, consequently, school) inequity" (p. 48). The complicated history of what constitutes property and how property rights govern spatial and social relations (Harris, 1992; Lipsitz, 2007) intersects meaningfully with citizen participation and is at the core of city and urban planning as well as the research projects that YRP takes on. Additionally, a CRT framework, as well as the organizational ethos of CoP, centers the lived experiences of participants and the way they bring their life stories to their community research to achieve their shared goals as counterstories that deconstruct master narratives and have a stake in policy change.

YRP conceptualizes and operationalizes CoP through a CRT lens. This application attends not only to the ambiguities around what CoP is (Storberg-Walker, 2007), but also compels practitioners to confront the potential for the uncritical abstraction and uptake of CoP. Elizabeth Alexander (2020) writes that "Community is a mighty life force for self-care and survival. But it does not protect against murder" (p. 22). While Alexander is not referring to Lave \& Wenger's CoP, her reflection on the word and thing, "community," brings into visceral relief the discursive weight loaded into the construct "community." It is both a romanticized yet necessary element of survival (Joseph, 2002). Alexander's reflection points to the tensions inherent in $\mathrm{CoP}$, of both the generative potential of understanding knowledge production, learning, and identity construction as happening within and across communities, 
as well as the dangerous limitations of not acknowledging how communities are situated historically within a broader cultural politics of power, and of race and racism in particular.

Because YRP makes racial and economic inequities central to its methodological and pedagogical design, it is necessary to also deploy a theoretical analysis of race and power in education to better understand how BMA students engaged with the YRP curriculum to relationally negotiate a sense of self, place, and identity through their communities and schools while asserting themselves as critical civic participants and urban planners. Aligned with the tenets of CRT outlined above, YRP can be understood as a CRT-application of CoP in the following ways: First, YRP endeavors to foster connectivity and bring together schools and cities, institutional bodies that - in theory - have in common the basic goals of protecting and educating vulnerable populations (Apple, 2018; Shor, 2012), but in practice, are seldom apprehended as mutually informing organizations, and have been shown to be historically exclusionary of, and damaging to, racially and economically minoritized people (Anyon, 1997; McLaren, 2015). Second, in bringing together civic agencies with schools and young people, YRP seeks to gradually shift our perceptual and physical orientations towards what constitutes space, property, the civic sphere, and what it means to feel a sense of belonging towards each of these things. In this way, YRP's focus is not only on cultivating and bridging communities of practice across schools and the civic sector, but also, gaining an understanding of and illuminating what it takes to achieve antiracist thinking and practice within and across implicated CoPs.

\section{METHODS}

\section{Data Collection \& Analysis}

The YPR methodology follows a Design-Based Implementation Research (DBIR) approach (Fishman et al, 2013) and mirrors a professional research process, guiding students through five steps, from partnering students with city leaders, to identifying community-based research questions, to collecting and analyzing data, generating solutions, presenting ideas publicly, and ultimately reflecting on the process. Learning outcomes are framed along a double-bottom line reflecting DBIR tenets by (a) building the capacity of young people to effectively contribute youth-driven data and insight to the planning and policy making process while developing college, career, and community readiness skills, and (b) building the capacity of civic leaders to value and use youth insight to create better plans and policies, and more equitable and sustainable spaces and places (McKoy, 2007).

Data include the authors' field notes; interviews and focus groups with students, teachers and civic partners; testimonies from students in YRP video documentation; studentgenerated community data and analysis including surveys, maps, presentation boards, and academic work such as poems, sketches, and photographic images of their school and community; and policy briefs written by students for civic partners. The case study method (Stake, 1995) allows us to examine multiple sources of data across multiple class contexts while privileging students' experiences as our unit of analysis. Data relevant to this paper were gathered between 2016 and 2018 across a total of one BMA teacher's five classes with 
97 students at a public urban high school ${ }^{2}$. Because the BMA curriculum is designed to support African American male students' academic, career, and personal endeavors, BMA classes are composed of African American male students.

YRP is housed in the Center for Community and School Connectivity (CCSC), a research center that examines relationships between cities and schools. This research center is housed in a large research university. Hillside Unified School District, in which Hillside High School is housed, has an existing relationship with the CCSC through which the YRP civic action research partnerships are cultivated in the interest of supporting teachers' projectbased learning skills and supporting students' college and career readiness. Access to Hillside High and the BMA classroom was facilitated through CCSC's partnership with Hillside Unified School District.

\section{Context: Place-based civic identity transformation}

This project took place within a city that is rapidly gentrifying, resulting in the displacement of predominantly Black and Latinx low-income residents, many of whom have lived in the city for generations. Since 2000, the city has experienced more than a $10 \%$ decrease in African American residents, marking a loss of more than 40,000 individuals. By contrast, the white population has risen by almost 30,000 people since 2000 (US Census Bureau, 2019). This shifting city demographic is salient in the population of its public school district. Between 2000 and 2018, the number of African American students enrolled in the city's school district was cut in half, and the percentage of the district whose students are African American dropped from almost half to less than a quarter.

The effects of this rapid gentrification are felt intensely at the urban comprehensive public high school where this case study is situated. While most of the city's public school students live in dense, urban areas in which a majority of the residents are people of color and low income, Hillside High School is situated in the rolling hills above the city, surrounded by natural beauty, expansive vistas, and a predominantly white, relatively affluent population. In 2000, Hillside served the same percentage of African American students and almost doubled the percentage of white students in the district overall. At the time, it was considered to be a "sought after" public high school for college going students. Today, African American students represent nearly one-third of the school's population, while they make up less than a quarter of the district's population. At the same time, the percentage of white students at this school is now less than that of the district as a whole (see Table 1).

This shifting demographic and economic landscape widens the gap between the experiences of civic leaders and the low-income residents that they serve. Additionally, the displacement of long-term residents exacerbates the distrust that low-income community members of

\footnotetext{
2 This number indicates the sum of the number of students enrolled during the introductory activity during each year. Note that due to the nature of enrollment and attendance at our urban public schools, some students left the classes, additional students enrolled in them, and not every student was present for every session. Additionally, six students were enrolled in the class both years.
} 
colour harbour towards their leaders, reinforcing the notion of "whiteness as property" (Harris, 1992) that has persisted since the nation's inception.

Table 1. Percent of African American and White Students by District and School

$\begin{array}{lllll} & 2000-2001 & & 2017-2018 \\ & \text { District } & \text { School } & \text { District } & \text { School } \\ \text { African American } & 47 \% & 47 \% & 24 \% & 31 \% \\ \text { White } & 6 \% & 12 \% & 10 \% & 7 \%\end{array}$

\section{Three Communities of Practice}

In the following case study, groups of Black male teenagers navigated multiple communities of practice, partnering with city and school leaders to collaboratively leverage their knowledge to shape policy-level decision making that impact their communities and schools. This was achieved through their involvement in two discrete projects: 1) the regional transit agency asked students how to better connect their local transit station with the surrounding community in order to increase youth ridership, and 2) the Mayor's office asked the students for their guidance in creating a more robust college-going culture in their school and community. In both cases, the civic leaders, under the guidance of the YRP team, posed these questions with the belief that these were city challenges that could only be solved in conjunction with young people.

This paper will focus on three CoPs: 1) the core BMA "School CoP" where the YRP project turned a classroom and high school campus into a CoP by bringing everyday life, authentic work, and the city itself to the school; 2) the nearby university "College CoP" through visits to and presentations on campus, university faculty and staff support, and mentorship from graduate and undergraduate students and alumni, and 3) the "City Planning CoP" as representatives from the regional transit agency and the Mayor's office visited classrooms, welcomed students to boardrooms, and hired them as interns. Although these three CoPs differed greatly in norms, language, symbols, and concepts, all three shared one central component: the young, Black men from the BMA classes were able to cultivate and exercise a form of agency that influenced a greater sense of civic belonging and civic identity development.

As the BMA students navigated through the three CoPs, we witnessed what Wenger (1999) calls a "social ecology of identity," in which "identities form in this kind of tension between our investment in various forms of belonging and our ability to negotiate the meanings that matter in those contexts" (pp. 188-190). Moreover, the very nature of the specific community development projects required affording increased sense of ownership of place to BMA students, thereby partially interrupting the construct of "whiteness as property" (Harris, 1992) that has transversed and predominated throughout American history. The resulting shared sense of ownership within those CoPs for their community is the foundation for these students' sense of agency and civic identity. We explore how in a country that equates whiteness with property (Harris, 1992), we can cultivate a CoP to facilitate civic inclusion 
and involvement for young, Black men with city, school, and academic leaders as they work to transform public spaces together. This work fosters an increased sense of place ownership for the students, which by leading to renewed responsibility and stewardship, helps them develop a greater sense of agency, and in turn leads to civic identity development.

\section{FINDINGS}

\section{Community of Practice 1: School}

As noted above, traditional classrooms lack key ingredients of CoPs, with both the power differential between teacher and students and the lack of a common unifying goal preventing its emergence. However, in this case, we witnessed the ability of the BMA classroom to transform into a CoP when students and teacher were able to share their lived experiences while working toward the common goal of their community development projects over two years. Although students were skeptical at first of working with outsiders from both the university and civic agencies, the consistency of collaboration during the first regional transit project prepared the School CoP to advance their shared goal of improving their city through collaborative participation with a second participatory action research project the following year; supporting the Mayor's office to create a "college-going culture" in their school and community.

With YRP staff acting as brokers bringing both the civic representatives and the city planning content to the School CoP, students wrote "Where I'm From" poems, designed and distributed surveys, and interviewed classmates and community members. In addition they researched best practices, conducted a SWOT (strengths - weaknesses - opportunities threats) analysis and brainstorming charrette, collaborated to craft proposals for their client, prepared for, presented, and reflected on the research process, outcomes, and presentations during each project. In both years, students' voices in the charge to improve their present and future education was of particular importance, as Ladson-Billings and Tate (1995) note: “...without authentic voices of people of color (as teachers, parents, administrators, students, and community members) it is doubtful that we can say or know anything useful about education in their communities" (p. 58). Student recommendations for regional transit included community centered design and policies from reimagining stations as 21 st Century Libraries to brightening their walls with locally inspired murals, to replacing armed security with "community protectors" who know the neighborhood to cultivate a sense of community within those walls.

Extending that community sentiment, the following year's recommendations for the Mayor's office centered on freedom and ownership. As a part of their YRP action research projects, students called for the creation of a space on campus designed for all students to access resources about how to prepare for, apply to, and persist through college. According to the students, such a place must be open for extended hours, occupy a central location on campus, and provide a comfortable, welcoming environment that all students feel is their own. Students also called for an overhaul of the cafeteria to ensure that they are offered healthy food options, nutrition classes, and that the cafeteria becomes: "a place you want to spend time and eat." Finally, students proposed overall wellness as being essential to a collegegoing culture, suggesting it should include additional counselors, nurses, and social workers 
as well as wellness officers instead of security guards. Students articulated these desires powerfully in a policy brief synthesizing their research process and recommendations:

In the absence of more mental health staff, teachers and staff could be trained to engage carefully with students. The solution isn't just to hire more counselors, but actually have people engage with students, like asking "What's going on?" having a general sense of caring on campus, like there's a place for you all to talk, and if you don't reach out, someone will reach out to you. 'Cause some people don't want to or are scared to. It would help the counselors too. By showing students more respect and trust and preparing them to make healthy choices on their own, we create not only a culture where students are prepared to go to college, but one where we are prepared to succeed when we get there.

In this way, students declared their definition of a college-going culture for their school and community by defining it as a place in which all students feel ownership, freedom, and the support of all the adults around them.

During both projects, students also considered their positionalities within the physical and perceptual borders of their school and questioned how their sense of belonging at school is situated within broader historical practices of civic exclusion. Despite its college campus feel, the restrictions on students' use of its space extend beyond its borders. This high school's campus is "closed," meaning that students are not permitted to come and go during the school day. During the spring of 2018, the primarily white, wealthy neighbors of Hillside High complained that students, the overwhelming majority of whom were low-income students of color, were congregating in their streets and walking past their houses before, during, and after the school day. In response, the school posted the following announcement on their website, and read it at the start of each school day:

A reminder to all students that Hillside High is a closed campus. All students must stay on campus and attend class. According to Hillside High and [...] district policies, all student drivers must not leave campus during lunch. Also, the surrounding neighborhood is not a place for students to loiter, cut class and engage in any inappropriate behavior at any time. All roads and areas [...] are private property [...] Students must refrain from loitering in the median on [...] boulevard. This is dangerous and poses a risk to both students and drivers. Be advised that the [Homeowner's Association] has and will be reporting students who are found trespassing to the [...] police. Students who choose to loiter in the neighborhood risk being detained by police for trespassing.

Piped into their classrooms by loudspeaker during their opening announcements, these words reminded students of color at the start of every school day for months that their presence in, and use of space is policed and disciplined on multiple levels and by multiple institutional arenas - such as the school, the police, and the Homeowner's Association. This "racialization of space," along with its corollary "spatialization of race" (Lipstiz, 2007) is 
highlighted in such cases when students of color, in this case Black male students in particular, attend school in a different place from where they live.

Black students' attempts to enjoy the expansive vistas and landscapes of their school campus are disciplined and criminalized with practices like "truancy sweeps" executed by school security guards and teachers that take punitive measures against students who are not in class when they should be. In fact, in an exchange with one of the authors, the BMA teacher noted that "for a lot of the students, this is the most open space they'll experience all day." The author further reflected in her field notes that "students who cut class for roaming the campus are in fact taking advantage of the meandering feel of what was supposed to be an open, college campus, and that the schools' disciplinary practices and culture do not reflect the space of the campus." These disciplinary and punitive practices emerge as an instance of misunderstanding the novel ways by which racially and economically minoritized youth mediate relationships to space and place, especially when the space and place is their school grounds. In the particular instance of their school, it seemed that BMA students and their fellow students of color sought to claim space, or "vote with their feet" (Duster, quoted in Neely \& Samura, 2011) by meandering around the campus, sitting on its many benches, walking along its perimeters even if these were someone else's "property". Although these "truant" students never left the school premises, their interactions with and presence on the campus grounds were not legible beyond frameworks of deviant behavior. As the work of critical race (Harris, 1992; Lipsitz, 2007) and race and space studies (Knowles, 2003; Neely \& Samura, 2011) scholars shows us, space is "historical, contested and fluid" (Neely \& Samura, 2011, p. 1934), and as such, is an "active archive" (Knowles, 2003, p. 79) reflecting centuries of resistance against civic exclusion and expulsion of minoritized individuals from the US civic landscape and spatial imagination.

The historical construction of Blackness as property and of Black individuals as uneducable subjects and bodies out of place (Dumas, 2014; Yancy, 2016), BMA students' (as well as other minoritized students') relationships to their campus space necessitates non-deficit and nonpunitive frameworks to understand how these students mediate relationships to their school physically and symbolically. Indeed, students' testimonies throughout the research process and during focus group reflections attest to their desire to "move around," "explore the campus," and "take advantage of the space [...] like we're supposed to," pointing to motivations to engage with school space in a positive capacity, as opposed to a lack of love for learning or pointed intentions to thoughtlessly frustrate school administration. In the words of one student, "we should be able to walk around, 'cause it's almost like a college. I know we're in high school, but because we're in high school we should have the freedom to walk around."

Students used the tools and pedagogical practices built into the YRP strategy to push the bounds of the research question to implicate systems and structures of civic exclusion and racial and economic oppression. Students showed how their "truant" behaviors are in fact playing with practices of belonging and civic inclusion at their school. In this respect, their school community of practice emerged as an instance of the kind of counter-space (ross et al., 2016) that needs to exist within historically exclusionary institutions like the school for 
students to be able to leverage their knowledge as an interruption to reproductive institutions and practices. ross et al. (2016) define a counter-space as a site of "shared collective accountability and authority" (p. 94) "where deficit notions of people of color can be challenged and where a positive collegiate racial climate can be established and maintained" (p. 70). Participation in the YRP project helped fortify the dimensions and ethos of the counter-space due to its emphasis on collaborative, social-justice oriented praxis. The focus on students' lived experiences and counter-stories as sources of viable knowledge was crucial to changing the way both students and adults thought, moved through and inhabited their physical environment, and imagined their future.

Students used the YRP strategy and pedagogical process to interrogate meanings of civic ownership and belonging and to negotiate a sense of ownership of the central public place in their lives - their school. In this way, the BMA students' School CoP played a central role in mediating students' increased sense of agency. As one student noted in a focus group in May: "I feel like this plan was effective because we made it all the way to the Mayor's office, we made it to talk to people with power to do things, I feel like we made a difference". By the end of the calendar year, the Mayor's office had not just heard the stories and ideas of the BMA students, but had also followed up on their proposals by opening a new center on campus to promote a college-going culture.

Students' data and engagement with the YRP strategy not only served to legitimize and buttress their research proposals as empirically credible, but also helped tell their stories, as well as the counter-stories that resist the continuing legacy of whiteness as property. The existing community of practice and counter-space in the BMA classroom set the premise for unique engagement with the YRP strategy where the students pushed the boundaries of the project question to exceed its conceptual parameters and implicate systems and structures of civic exclusion and racial and economic oppression. By reflecting on their campus culture, school practices and norms, and the ways in which schooling has shaped their life trajectories and is shaping their futures, students also reflected on their own racialized subjectivities. As this agency and increased sense of ownership led to the cultivation of a civic identity in the young people, adult perceptions within the School CoP shifted as well. As the BMA teacher noted after the first project, "I was concerned that it was almost too advanced, however I'm glad that it was, the curricular aspect supplemented our curriculum and we used it as an opportunity to do some community development." In this way, the teacher, himself a member of the School CoP, demonstrated increased expectations of his students, while his use of the term "we" in the above quote indicates his perception of his own membership of this CoP, working together toward the shared goal of improving their community.

\section{Community of Practice 2: College}

Throughout the [college tour] field trip students were greeted by other Black students walking around, we continuously ran into the [tour] guides' friends and colleagues - there was always someone saying hello, and all made the same remark - "it's good to see so many Black faces on campus." (Gamez-Djokic, Field Notes, 4/9/2018) 
Throughout the spring semesters of 2017 and 2018, college mentors from an aligned YRP university studio seminar supported the BMA students by visiting their classroom once a week. They provided city planning content, helping to facilitate their project and serving as college-going role models for the high school students. During the spring of 2017, despite enjoying the mentors' support, the BMA students distanced themselves from the university in a variety of ways. One student leader expressed such contempt for the university that he refused to eat the food they provided when first on campus with the YRP team. A month later, he committed to speaking at a high-profile campus event, only to disappear from school minutes before the YRP team member was scheduled to pick him up. Another student, a bright and motivated freshman, explained that while he used to want to go to that university, he had changed his mind after spending time there as part of an after-school program. He said that there were so few African American students on campus that when the program paired him with a mentor to show him the "Black student experience," his partner was not African American, but rather an international student from an African country. The transformative moment in the sense of ownership of place the BMA students felt for the university campus emerged during the college tour for the BMA YRP students.

Instead of a traditional tour, the BMA campus trip leveraged the personal relationships of the college mentors, coaches, and coordinator to introduce the BMA students to the specific resources for African American students on campus. The student who had expressed his concern that the college was unable to show him any students with whom he identified found a different outcome on this tour. Perhaps the most salient among them was the way that their undergraduate tour guides (who volunteered through their affiliation with the campus Black Resource Center) discussed the significance of "fighting for space" and "making space" for themselves when they occupy such little space as a $2 \%$ minority. The undergraduate students explained how student-of-color spaces like the Black Resource Center had to be fought for by Black students because previously no such space existed for them. By discussing how this is one of few spaces where Black undergraduate and graduate students can come just to hang out, get help with school work, and learn about how to access important resources, and by being able to see students hanging out in the actual space, the BMA students were afforded a sense of the figurative qualities of physical space that exceed the material, such as the camaraderie and comfort that one feels in a space in which they are welcome.

This affective sense of closeness is something that the BMA students experienced almost immediately upon their arrival on campus. As they waited in a group for the tour guides to arrive, they were greeted by multiple Black students passing through campus, commenting on how nice it was to see so many Black faces. Significantly, there were at least two undergraduate tour guides involved in the field trip who were alums of Hillside High, which allowed the BMA students to not only see their school represented at a large research university, but also to get a sense of how communities of practice can both contract and expand. This seemed to have an impact on the BMA students' sense of exclusion from college spaces like the university. After a panel discussion during which BMA students had the chance to ask the undergraduate students questions and interact with them in small groups, 
one student remarked, "I learned that I shouldn't be afraid to apply to a place like this." This stood in sharp contrast to students' remarks before embarking on the campus visit, such as "my grades aren't good enough," or "my GPA isn't high enough," or "I don't think I'm ready to apply to college yet." The students' fear and doubt in their own capacities were mitigated by their expanded community of practice, their interactions with the undergraduate students, and other affiliates of the Black Resource Center.

Thus, the BMA students came to campus not as outsiders, in the way "black students often come to the university in the role of intruders-who have been granted special permission to be there" (Ladson-Billings and Tate, 1995, p. 60), nor did they come with the anonymity typical of potential applicants on a slate of college tours. Instead, the BMA students came to the university as members of their College CoP. Their partnership and existing relationships with college mentors, coaches, and the coordinator welcomed them into the small, but tightknit family of Black students on campus. When students who had previously reported not feeling comfortable at the university realized "I shouldn't be afraid to apply to a place like this," they began to own their ability to thrive at this major university. After the tour, the BMA teacher mentioned several times that the field trip was the most meaningful trip he had ever taken with the students, and several students mentioned that it was one of their favorite parts of the YRP process as well.

Two weeks after the college tour, representatives from the BMA classroom returned to the university campus to present their proposals as part of a regional summit that included more than 200 students, educators, and civic leaders from across the region. Building on their confidence from the tour, the young men owned their presentations, engaging confidently with all participants. In the afternoon session, the young man who had reneged on his commitment to present with the dean the previous year now served as the student voice on a campus-hosted panel of city, regional, and educational leaders. According to his friend, this student had not attended school in weeks, as his presence was required at home to care for an ill parent. Nevertheless, he made sure to attend the summit. On the panel, he explained to the audience of civic and academic leaders as well as other students that he had resisted involvement during the spring of 2017 not out of fear, but because he "didn't believe that our ideas would be heard." He did not miss the opportunity to present in 2018, however, because he now believed that "this is for real." The student encouraged his peers from across the region to engage in their schools and cities, to confidently share their ideas, to speak their truth, while enlisting the civic leaders present to continue to seek youth insight and to take the time to listen, "even if it takes years." The young man demonstrated his increased sense of civic agency by owning the stage at a major university, imagining and believing in a future "[w] here language flows freely and existence is nurtured and resistance is breath. Where the Black educational imagination dances wildly into the night—quenching the thirst of yearning and giving birth to becoming" (Dumas \& ross, 2016, p. 436).

Engaging not just with each other, but with college students, university faculty and others in the university context deepened the understanding of students in this College CoP that this was not just another school assignment to teach them what college is supposed to be like; 
this was college level work, offering an opportunity for these students to envision themselves as college students, alongside their mentors.

\section{Community of Practice 3: City Planning}

We make up [our city] 'cause without us everything that is here is just land. Our ideas and stuff is what make [our city], [our city]. (Student, YRP Video, 2018)

The initial YRP "civic client" for the BMA classes, the regional transit agency, first met the students when representatives visited their classroom to present their PowerPoint project. That day, the reality of the differences in class, race, and culture between the transit professionals and the students in the third City Planning CoP emerged quickly, as the students openly discussed their sadness and anger over the recent death of yet another classmate with the BMA teacher and YRP team, while their civic client representatives sat silently, listening with a disposition and distance that suggested a level of social and cultural removal from the realities the students conveyed in their heartfelt testimonies. Though the students were aware of the presence of outside professionals, they did not censor their words for anyone's benefit. By meeting the students first in their classroom, and as observers in this raw conversation, those representatives from the transit agency experienced and interacted with the BMA School CoP in action. This initiated the evolution of a new City Planning CoP tasked with the goal of improving their city by better connecting their local transit station to its surrounding community and increasing youth ridership in the process.

In their role within the City Planning CoP, the transit agency representatives who visited the classroom facilitated a design tour for the students, showing them a newly redesigned station and the inside of their boardroom. The tour culminated with a site mapping of the station the students would explore for their project. While the expectations of the School CoP were familiar to the students, the norms of membership in this City Planning CoP required negotiation by all parties involved.

This entrance for the BMA students into the divergent norms of the City Planning CoP began at a local transit station, where agency officials led students on a facilities tour before boarding a train to their corporate headquarters. Once in the agency boardroom, in preparation of the Deputy General Manager's (GM) welcoming remarks, the YRP team stepped up to quiet the students. While many students acquiesced quickly, some students wore headphones, had their heads on the desk, or wore hoods or hats, and others kept talking. Within about a minute, the students had settled to a low murmur. Rather than waiting for the final few to follow suit, one agency representative who had not previously met the students stepped to the front and demanded that all students remove hats, hoods, headphones, and sit up straight immediately as "that behavior is not permitted in our boardroom." As Ladson-Billings and Tate (1995) explain, "[w] hen students are rewarded only for conformity to perceived 'white norms' or sanctioned for cultural practices (e.g., dress, speech patterns, unauthorized conceptions of knowledge), white property is being rendered alienable" (p. 59). Students refused the charge of "unprofessional" behavior, exposing colorblind policies and practices that construct minoritized students' dress and behavior as deviant. The noise level grew during her demands, and although most students 
eventually quieted, the tone shifted as she yielded the floor to the Deputy GM who spoke briefly to the students, welcoming them to headquarters, over their chatter. Following the career panel and lunch, students left headquarters to map their focal transit station. Through the challenges of navigating new norms and expectations, the young people were exposed to authentic places, resources, tools, professionals, and the inner workings of the regional transit agency on the tour.

Despite the struggles during the trip, the City Planning CoP proved transformative for young people and adults alike. Although some agency representatives who had not previously met the students and were not members of their City Planning CoP conveyed their frustration and disappointment with student behavior, the transit employees who had visited the students first in their classroom responded differently. Their frames of understanding minoritized youth and urban schooling began to shift from a focus on pathologization of student behavior, to a nascent understanding of the way racially and economically minoritized youth engage with space and make sense of practices of systemic disinvestment. For example, during the train ride, one representative from the transit agency had noticed a student sitting alone and sat next to him. He was sketching in a book. She told him she liked his art and that she would love to have him design a mural as part of the project. He never looked up at her. He never said a word. Later in the day, she walked alongside him at the station, pointing out a good spot for a mural, and reminded him of their earlier conversation. Again, he stared at the ground as she spoke. She asked his name, and he mumbled it to her. He never looked at her, acknowledged her suggestion, or showed her any outward sign of "respect." She thought he was not listening but remembered his name. A month later, as his School CoP grieved yet another classmate, this young man sat quietly in the back of the room, sketching the train station as he envisioned it: dueling suns shone overhead, equally illuminating both sides of the tracks.

When she learned of the sketch, the adult who had previously reached out to him as a member of her own CoP was struck by the power derived from this seemingly simple connection. She understood that the CoP would benefit from the unique talents of all members and demonstrated confidence that by virtue of his lived experiences and unique knowledge, this teenager had the potential to improve the transit station in a way she could not. This connection, the sort of which can be uniquely forged through the power of a CoP in which members from vastly different backgrounds share a common purpose, became the foundation for a set of paid summer internships the regional transit agency ultimately created to further harness the artistic insight and creativity of the BMA students.

A month later, after students had already presented at City Hall, the transit agency invited four student representatives to present to more than fifty managers at their quarterly meeting. When they finished, the GM took the microphone and spontaneously announced the creation of funded internships for these young men to implement their ideas over the summer, and he called for volunteers to facilitate those internships from the managers present. On June 26th, seven young men, including the young artist, embarked upon their paid summer internships to implement their recommendation of a community 
mural. Over the course of the summer, they designed the scope of the mural, put out a call for artists, reviewed submissions, and selected the muralist to complete the project.

During the course of the internships, a shift in agency was apparent in the way the students presented themselves, described the process, and impacted the transit agency itself. As one student explained " $[\mathrm{w}] \mathrm{e}$ are contractors so we planned out a mural and with that mural we're fitting to put our ideas from the culture of [our city] out. How we all perceive [our city] as people who actually live here and not people outside it." Moreover, according to the Art Program Manager who oversaw the internship identified the students' desire for the permanence of their ownership of place when she noted that "[w] hat was really resonating with the team was how much these students want this piece to last. They don't want it to be here and gone. They would love to see this to be the first of many mural projects that express who they are as a community." Although the installation took almost three years, several members of this City Planning CoP, including students, transit officials, the BMA teacher, and YRP staff reunited to celebrate together at its unveiling ceremony.

In addition to the mural, several other suggestions made by the BMA students have taken hold within the regional transit agency, and others have continued to be discussed. As a result of this project, the agency raised the age for youth fares from 12 to 18. Sales of youth tickets more than doubled in the first year of the change. They modified ticket machines to accept smaller bills, as students pointed to the difficulty of purchasing tickets without a credit card or a large bill, which would then return change in coins. In the face of increased pressures to add police and security guards to stations, the agency continues to revisit the youth's suggestion of replacing officers with a force of "Community Protectors." In the students' vision, “Community Protectors would be community elders who are hired to oversee station safety. They should be unarmed, unaffiliated with the police, and trained in nonviolent conflict mediation. These Community Protectors would improve the feeling of safety in stations while also connecting visiting passengers to local businesses. We envision Community Protectors as being local people who know the area and care about its safety and wellbeing."

During the 2018 project, even as the locus of place shifted from city to school grounds, the City Planning CoP thrived in partnership with the Mayor's office, culminating with a roundtable presentation in the Mayor's conference room. By inviting the BMA students into the personal boardroom of the Mayor for an intimate roundtable with city leaders, this event itself brought Black male teenagers not just into sight, but centered them in defining the future of the places that matter most to them. Moreover, it facilitated students' imagining themselves and (counter)-telling their experiences into the transformation of space and place.

\section{Discussion \& CONCLUSION}

YRP provided a natural setting for CoP members across sectors and organizations and racial divides to share their stories, to build relationships that would not exist without this process, and to seek solutions to shared challenges together; as such, the YRP strategy addresses a 
void in situated learning theory of examining the role of race, not as an impediment, but as the facilitator of this powerful experience.

We identify the following three outcomes on a student level: 1) engaging with questions of race, space, and place facilitated explorations of identity and civic agency that complemented learning while serving a humanizing function for BMA participants, 2) although research questions did not explicitly implicate systems and structures of oppression, students leveraged their experiential knowledge to situate recommendations within a broader recognition of systemic racism, and 3) after completion of civic action projects, students and teachers reported an increased sense of belonging for students both in school and in their city.

On an adult and civic level, we identified two major outcomes: 1) when youth are brought "to the table" both figuratively and literally, stakeholders are reminded of the positions of power they hold and the obligations they have to be accountable to disenfranchised youth, and 2) adult stakeholders in positions of power rarely hear youths' testimonies of their experiential relations to their built environment; bearing witness to their stories illuminated the necessarily affective nature of pedagogy, planning, policy-making, and citizen belonging at large.

The fourth phase of the YRP research strategy is often reported as one of the most impactful parts of the research process for both students and teachers because students are able to showcase their work to stakeholders and see their visions for change manifest on both an ideological and material level as relationships between adults and youths, stakeholders and community members, schools and students, and (built) environment and individuals change. For BMA classes in particular, partaking in these changes has a salience that brings to light students' unique positionality as Black males within both macro-level and micro-level racial hierarchies. YPR research findings show that BMA youths' sense of belonging within their schools and larger community is one premised on feeling included, heard, dignified, and respected.

As youths move through the YRP process, they have the opportunity to situate themselves in time and space physically and metaphorically - whether through poetry or "mapping" spaces by foot, word, sketch, or memory, students use these research tools to explore and negotiate the spatial and temporal dimensions of their racialized belonging (Lipsitz, 2007). CoP strategy tends to overlook these particular relationships to delineate and explore the parameters of youths' civic inclusion in this way. This paper thus has important implications both for education praxis and design-based research at large that seeks to resist racialized exclusion of youth by upholding marginalized students' voices and narratives, instead making them central to research, policy, and city planning. 


\section{REFERENCES}

Alexander, E. (2020, June 15). The Trayvon generation. New Yorker. https://www.newyorker.com/magazine/2020/06/22/the-trayvon-generation

Anyon, J. (1997). Ghetto schooling: A political economy of urban educational reform. Teachers College Press.

Apple, M. (2018). Ideology and curriculum. Routledge.

Duguid, P. (2012). 'The art of knowing': Social and tacit dimensions of knowledge and the limits of the community of practice. In D. Livingstone \& D. Guile (Eds.), The Knowledge Economy and Lifelong Learning (pp. 147-162). Brill Sense.

Dumas, M. J. (2014). 'Losing an arm': Schooling as a site of black suffering. Race Ethnicity and Education, 17(1), 1-29.

Dumas, M. J., \& ross, k. m. (2016). "Be real black for me" imagining BlackCrit in education. Urban Education, 51(4), 415-442.

Flores, M. T. (2007). Navigating contradictory communities of practice in learning to teach for social justice. Anthropology \& Education Quarterly, 38(4), 380-404.

Harris, C. I. (1992). Whiteness as property. Harvard Law Review, 106(8), 1707-1791.

Joseph, M. (2002). Against the romance of community. University of Minnesota Press.

Knowles, C. (2003). Race and social analysis. Sage.

Ladson-Billings, G., \& Tate, W. F. (1995). Toward a critical race theory of education. Teachers College Record, 97(1), 47.

Lave, J., \& Wenger, E. (1991). Situated learning: Legitimate peripheral participation. Cambridge University Press.

Lipman, P. (2012). Mixed-income schools and housing policy in Chicago: A critical examination of the gentrification/education/'racial 'exclusion nexus. In G. Bridge, L. Lees \& T. Butler (Eds.), Mixed communities: Gentrification by stealth (95-113). The Policy Press.

Lipsitz, G. (2007). The racialization of space and the spatialization of race theorizing the hidden architecture of landscape. Landscape Journal, 26(1), 10-23. 
McLaren, P. (2015). Life in schools: An introduction to critical pedagogy in the foundations of education. Routledge.

McKoy, D. (2007). The community development and education connection. Community Investments, 19(Fall), 20-21.

McKoy, D., \& Vincent, J. (2005). The Center for Cities \& Schools: Connecting research and policy agendas. Berkeley Planning Journal, 18(1).

McKoy, D. L., \& Vincent, J. M. (2007). Engaging schools in urban revitalization: The Y-PLAN (Youth-Plan, learn, act, now!). Journal of Planning Education and Research, 26(4), 389-403.

Neely, B., \& Samura, M. (2011). Social geographies of race: Connecting race and space. Ethnic and Racial Studies, 34(11), 1933-1952.

ross, k. m., Nasir, N. I. S., Givens, J. R., de Royston, M. M., Vakil, S., Madkins, T. C., \& Philoxene, D. (2016). "I do this for all of the reasons America doesn't want me to": The organic pedagogies of Black male instructors. Equity \& Excellence in Education, 49(1), 85-99.

Shor, I. (2012). Empowering education: Critical teaching for social change. University of Chicago Press.

Solorzano, D., \& Yosso, T. (2000). Toward a critical race theory of Chicana and Chicano education. In C. Tejeda, C. Martinzez \& Z. Leonardo (Eds.), Charting new terrains of Chicana (o)/Latina (o) education (pp. 35-65). Hampton Press.

Stake, R. E. (1995). The art of case study research. Sage.

Storberg-Walker, J. (2008). Wenger's communities of practice revisited: A (failed?) exercise in applied communities of practice theory-building research. Advances in Developing Human Resources, 10(4), 555-577.

U.S. Census Bureau. (2019). Quick Facts. https://www.census.gov/quickfacts/fact /table/US/PST045219

Vincent, J. M. (2006). Public schools as public infrastructure: Roles for planning researchers. Journal of Planning Education and Research, 25(4), 433-437.

Wenger, E. (2010). Communities of practice and social learning systems: The career of a concept. In C. Blackmore (Ed.), Social learning systems and communities of practice (pp. 179-198). Springer.

Yancy, G. (2016). Black bodies, white gazes: The continuing significance of race in America. Rowman \& Littlefield. 


\section{BIOGRAPHICAL Note:}

Amanda Eppley brings experience in schools, city planning, and technology to her work at the University of California, Berkeley Center for Cities + Schools $(\mathrm{CC}+\mathrm{S})$. An experienced educator, Amanda has taught middle and high school English and history at urban and suburban public schools in California and Massachusetts. Additionally, after earning a Master's degree in City Planning from UC Berkeley with a concentration in Environmental Planning, Amanda has facilitated equitable school planning and design processes and has served on her local planning board. In her previous roles as Y-PLAN Program Manager at $\mathrm{CC}+\mathrm{S}$, Amanda led Y-PLAN systems expansion in New York City and in California. Meanwhile she has leveraged experience as a software engineer and database developer to improve $Y$ PLAN's website and CC+S's data management systems. In her current role as the Center's Associate Director, Amanda develops and provides training on Y-PLAN content, cultivates school, community, and civic partnerships, and manages action research initiatives.

Blanca Gamez-Djokic is a Ph.D. candidate at the University of California, Berkeley Graduate School of Education. Blanca's research interests pivot around emotion, affect, critical pedagogy, schools, practices and processes of racialization, and school-community partnerships. Blanca has a B.A. in Sociology and Anthropology from Swarthmore College and an Ed.M. in Arts in Education from Harvard Graduate School of Education.

Deborah L. McKoy is the Executive Director and Founder of the UC Berkeley Center for Cities and Schools at the Institute of Urban and Regional Development and a lecturer in the Department of City and Regional Planning and the Graduate School of Education. Her research and teaching focuses on the intersection of educational reform, urban \& metropolitan planning, community development, and public policy. Central to her work is the critical role young people play in urban and metropolitan change and transformation. For over two decades, Deborah's work has bridged the worlds of research, policy and practice, including a wide range of professional experiences: Consultant to the US Department of Housing and Urban Development (HUD); Chief of Economic Development at the NYC Housing Authority; Director of Refugee Services for CAMBA, a NYC non-profit organization; and Consultant to the United Nations Education For All initiative. Deborah has published numerous articles and reports for academic and peer reviewed journals and her work and teaching has won a range of awards. 